\title{
Poverty in the Eyes of Brazilian Elites
}

\author{
Elisa P. Reis*
}

September 2010

\begin{abstract}
This paper discusses data from a survey and in-depth interviews on elite perceptions of poverty in Brazil. De Swaan tried to identify the circumstances under which elites are willing to mobilize resources in order to promote poverty reduction. This paper questions if de Swaan's analysis applies to Brazil. The main finding is that two parts of de Swaan's thesis do apply: that poverty is a problem for the rich in the sense that it generates negative externalities that they would like to reduce; and that the elite believe that there are effective remedies. What is missing for Brazilian elites is the third element, namely that the elite see poverty as their responsibility to do something about it.
\end{abstract}

Keywords: elites, poverty, economic sociology, political culture

JEL classification: Z13

\section{Copyright (C) UNU-WIDER 2010}

* Universidade Federal do Rio de Janeiro, Brazil. E-mail: epreis@alternex.com.br

This study has been prepared within the UNU-WIDER project on The Role of Elites in Economic Development, directed by Alice Amsden, James Robinson, and Alisa DiCaprio.

UNU-WIDER gratefully acknowledges the financial contributions to the research programme by the governments of Denmark (Royal Ministry of Foreign Affairs), Finland (Ministry for Foreign Affairs), Sweden (Swedish International Development Cooperation Agency-Sida) and the United Kingdom (Department for International Development-DFID). 


\section{Acknowledgements}

Research used in this article was made possible by grants provided by the North-South Center of the University of Miami, and by two agencies of the Brazilian Ministry for Science and Technology, respectively FINEP and CNPq. The author also wants to acknowledge the criticisms and comments made by Alice Amsden, James Robinson, and Alisa DiCaprio. While I have greatly benefited from their valuable suggestions, the usual disclaims apply.

The World Institute for Development Economics Research (WIDER) was established by the United Nations University (UNU) as its first research and training centre and started work in Helsinki, Finland in 1985. The Institute undertakes applied research and policy analysis on structural changes affecting the developing and transitional economies, provides a forum for the advocacy of policies leading to robust, equitable and environmentally sustainable growth, and promotes capacity strengthening and training in the field of economic and social policy making. Work is carried out by staff researchers and visiting scholars in Helsinki and through networks of collaborating scholars and institutions around the world.

www.wider.unu.edu publications@wider.unu.edu

UNU World Institute for Development Economics Research (UNU-WIDER)

Katajanokanlaituri 6 B, 00160 Helsinki, Finland

Typescript prepared by Janis Vehmaan-Kreula at UNU-WIDER

The views expressed in this publication are those of the author(s). Publication does not imply endorsement by the Institute or the United Nations University, nor by the programme/project sponsors, of any of the views expressed. 


\section{Why focus on elites in poverty studies?}

Research on elite perceptions is grounded on the premise that, under given circumstances, elites may perceive the consequences of poverty as being detrimental to their own interests. Contrary to common sense views, I argue that elites may be inclined to champion anti-poverty measures. Instead of taking for granted that elites are indifferent, or even interested in the perpetuation of poverty, I assume that those at the top of the stratification may find it suits their interests to support policies aimed at reducing poverty. However, the conditions required for this are not likely to occur often. I surveyed Brazilian elites to investigate what are the prospects for their willingness to reduce poverty and inequality.

Brazil has been widely reported to be one of the most unequal countries in the world (Barros et al. 2000). And at the same time, it has not been subject to revolt by the poor. This raises the question of what holds together groups and classes with such disparate life prospects. Related to this, how do those at the top, the elites, interpret issues of poverty and inequality? Sociologists and political scientists had somehow searched for answers to the first question, but even today there are very few studies dealing with the second one, namely the perceptions about poverty by the non-poor. There are indeed many case studies of how the poor themselves perceive their plight, how they explain their destitution and what they do to cope with it (Lewis 1959; 1966; Ellwood 1988; Small and Newman 2001). But, little has been said about the view of those at the top of the social structure, as if the poor and the non-poor belonged to different worlds (exceptions here are Verba and Orren 1985; Verba et al. 1987).

While much has been said about the ways poor people perceive their situation and devise strategies to cope with it, we know much less about the perception of poverty and inequality among the non-poor in general and the elites in particular. Quite often, ideological and normative arguments are invoked to discard the focus on elites in poverty research. To some, the mere option for studying the better-off already implies a disregard for those at the bottom of the society. To others, to accept that the wealthy have strategic power is to prevent those plagued by poverty from being empowered so as to be able to escape their plight. Yet, such prejudiced views can prevent us from gathering crucial information on the conditions for the success of anti-poverty policies.

To some extent, it is true that the life prospects of the poor and the elites are so disparate that they do belong to different worlds. But, it is also true that in sharing a common space and a common nation-state they affect each other and that their actions and inactions have consequences for the other. However, even within the academic and public policy communities, there seems to be little awareness that, since poverty and inequality are overlapping issues in a given society, it is urgent to understand how those at the top of the social structure see poverty in cognitive and normative terms. As a matter of fact, poverty and elite are words that seldom appear together in lay or even professional discourse. When they do, it is usual for them to convey one of two possibilities: to blame the elites for the existence of poverty, or else to exhort elites to be compassionate and help the poor. Often elites are perceived as detrimental to the poor, and the prospects for change seem to be conditional to changes in morals. The implicit prescription is to seek the conversion of elites to a virtuous disposition to help the poor. 
To say that the elites matter when we discuss poverty and inequality is not to ignore that pressures from below are very relevant to the issue at hand. Often the elites' attitudes and behaviour are a response to such pressures. In any case, short of revolutionary situations, the established elites necessarily play a key role in supporting and/or implementing actions or inaction vis-à-vis the poverty issue. It is important to make it clear that focusing on elites does not necessarily make the claim that poverty exists because the elites hold certain values and attitudes. Nor do we have to suppose that, because poverty exists, the elites invent certain beliefs to rationalize it. The relationships between beliefs and values on the one hand, and, on the other, material interests are the subject of endless epistemological questions that should not concern us right now. In the present context, it is sufficient to accept that values and interests are analytical dimensions that in real life affect each other.

Taking into account that elites control symbolic and material resources in a given society, how they conceive of poverty and inequality has decisive implications as far as anti-poverty measures are concerned. Since policy decisions involve a political community, the perspective of those who occupy privileged positions cannot be ignored. Acting preventively or reacting to pressures from below, elites are strategic actors that cannot be neglected when we inquire into the prospects for poverty reduction and for social redistribution. To inquire into the viability and effectiveness of particular social policies, one has to figure out how it is perceived by those who have power and influence.

This paper draws theoretical inspiration from the pioneering book In Care of the State, by Abram de Swaan on the historical origins of health, education, and welfare policies in Europe and in the United States (de Swaan 1988). In the book, he shows that the awareness of social interdependence between the poor and the non-poor among European elites prompted them first to act, and later on to pass on the task, to public authority, therefore establishing the path that finally led to social welfare policies. Combining theory and historical analysis, de Swaan shows that, when the elites became aware that poverty had negative externalities that affected their own life, they concluded that it was in their interests to alleviate poverty.

Working from this assumption, de Swaan sketched a model of the conditions under which the wealthy felt the urge to do something to ameliorate poverty. As he indicates, some conditions have to be met before the non-poor make the effort to reduce poverty:

a) First, elites have to perceive poverty as something that carries negative consequences to themselves. This could be the possible threat posed by certain actions on the rest of the poor. Thus, from the elites' perspective, it could be that those at the bottom might stage riots and revolts that would endanger social order. Or the poor might simply opt to exit, therefore reducing labour and/or consumption, or else depriving the army of soldiers. Last but not least, the fear that the destitute could endanger general health by spreading contagious diseases also constituted a powerful motivation behind efforts to improve sanitary conditions that contribute to better living standards for the poor.

b) Second, elites have to feel that there exists the possibility of reducing the evils of poverty. If no opportunities for action are identified or if elites feel 
powerless to act, there is no reason to expect they will respond to perceived negative externalities of poverty.

c) Third and last, the elites have to experience a feeling of responsibility for counteracting poverty. They have to feel involved, or else, why bother?

In short, the first condition of the model refers to awareness of social interdependence, the second to feelings of efficacy, and the third to a sense of social responsibility. If these three conditions are met, de Swaan argues, then it is possible to say that the elite are socially conscious (de Swaan et al. 2000).

The detailed historical analysis provided by de Swaan (1988) makes is quite convincing in showing that the elite first took the handling of poverty alleviation measures directly into their hands. The parish records for England, for example, make it quite clear that, initially, the wealthy accepted this responsibility. Both the stimulus of the ideologues with their exhortations, and the social constraints exerted by common parishioners were the major mechanisms to promote collective elite action. Yet, the inevitability of free riders ended up making it clear that authority coordination would be necessary to enforce a generalized contribution in the battle against poverty. Under such circumstances, the state became the natural actor to enforce health measures, to distribute food to the hungry and to improve living conditions in general.

The explanation de Swaan offered for the emergence of social policy is not based on altruistic motivations. Instead, he takes self-interest to be at the center of the motivation to act so as to alleviate poverty. Although recognizing that idealistic motivations prompted the ideologically motivated activists who contributed to mobilizing public opinion, his model explicitly assumes that interests are what move the world. Trivial as such an observation is, in poverty studies, this constitutes a significant rupture with the mainstream. Instead of resorting to compassion and altruism to explain how those at the top of social stratification agree to help the poor, de Swaan places self-interest as a possible motivation behind anti-poverty and redistribution measures.

Would one find among elites in Third World countries similar perceptions as the ones that de Swaan identified in the history of European elites? What would a survey study reveal about Brazilian elites? Impressionistically, there is strong indication that the historical European pattern is not being easily repeated in the Third World. This should not surprise us given the differences in economic, political and cultural factors. However, past experiences in dealing with poverty may contribute to the clarification of present day challenges and suggest the formulation of alternative hypotheses. Assuming that the more privileged sectors of society always confront the need for solutions to negative externalities of poverty, it follows that the preferred solutions derive from the perceptions the elites have of their own position in the market; the state regulatory capacity; and the strategies and tactics of the underprivileged.

\section{Surveying the perception of poverty among Brazilian elites}

Seeking to assess if Brazilian elites might seriously commit themselves to reduce poverty, in the 1990s I conducted a survey of 300 people who occupied leading institutional positions in the country (Reis 2000). Later the survey was complemented by a study based on in-depth interviews with 80 members of the elite. The in-depth 
study was part of a larger project conducted in five countries: Bangladesh, Brazil, Haiti, South Africa, and the Philippines, which afforded the opportunity for some comparison between Brazilian and the other national elites that are referred to below (Reis and Moore 2005).

Opting first for survey techniques and later for semi-structured interviews, this study was not a study about facts, but neither was it limited to opinions, which are more volatile manifestations of preferences (Reis and Cheibub 1995; 1996). What was investigated was the elites' political culture, their deeper beliefs and values about such questions (Munch 1992; Wilson 1992). What sort of explanations do they offer to justify or condemn persistent poverty and inequality? Who do they tend to blame for the fate of the poor? Do they identify consequences of poverty for the non-poor as well? What do they think should and/or could be done about the problem? Who do they see as primarily responsible for taking action against poverty?

As already indicated, the definition of elites adopted here refers to powerful people who control symbolic and material resources. Moreover, for the survey (as well as for the qualitative study to be discussed in the next section) the option was for an institutional criterion for being an elite. This is to say, individual elite members were contacted because they occupied top positions in selected institutions and not by reputation criteria. For sample purposes, four elite sectors were selected: politicians, top public officials, business leaders, and union leaders. As representative of the political elite, we selected members of the legislative power at the federal level. The technocratic elite was selected among top public officials in the federal administration. Business leaders were selected among the CEOs of the 300 largest firms in the country. Finally, union leaders were selected among the presidents of the larger unions in the country according to the National Census Bureau. The total sample comprised 320 cases spread over a few regional states and the federal capital, Brasilia (Lima and Cheibub 1994). All institutions selected had national, not just regional, power and influence.

The results of the survey indicated that, in general, the elites placed poverty among the top problems of the country. As seen in Table 1, a significant percentage of the respondents list lack of education first, and poverty and inequality second when ranking the major obstacles to democracy in the country. Together these two social issues comprise almost half of the responses (47.5 per cent) and are much more salient among the elites than specific political problems, like lack of party tradition or of popular organizations. It is interesting to observe that the threat of new military coups is not even considered to be a problem.

The same sort of perceptions show up when we inquired, not about obstacles to democracy, but just what were the most relevant problems the country faced in the elite's view. Once again, social problems rank high, second only to inflation that, at the time of the survey study, was very alive in Brazil's memory. As shown in Table 2, for the elites, lacking education and poor health conditions are second only to inflation. 
Table 1: Major obstacles to democracy in Brazil (\%)

\begin{tabular}{lc}
\hline \multicolumn{1}{c}{ Obstacle } & Total sample \\
\hline Low educational level of the population & 24.1 \\
High levels of poverty and social inequality & 23.4 \\
Lack of party tradition & 15.8 \\
Corporatism of groups and sectors of society & 10.4 \\
Incompetence of power incumbents & 6.0 \\
Lack of popular political organization & 5.4 \\
Selfishness of the elites & 4.7 \\
Political clientelism & 3.8 \\
Too much power in the hands of the executive & 3.2 \\
High inflation rates & 1.3 \\
Impoverishment of the middle class & 1.3 \\
Prolonged economic recession & 0.6 \\
Threat of military intervention & 0.0 \\
Total & 100.0 \\
\end{tabular}

Table 2: Brazil's most important problems (\%)

\begin{tabular}{lc}
\hline \multicolumn{1}{c}{ Problem } & Total sample \\
\hline & \\
Inflation & 17.5 \\
Education/health & 15.9 \\
Poverty & 14.3 \\
Governability & 11.5 \\
Income distribution & 8.3 \\
Other political issues & 8.3 \\
Other economic issues & 5.4 \\
Corruption & 4.8 \\
Recession and unemployment & 4.1 \\
Behaviour of the elites & 3.5 \\
Foreign dependence & 3.2 \\
Moral crisis & 2.2 \\
Other social issues & 1.0 \\
Total & 100.0 \\
& $(\mathrm{n}=314)$ \\
\hline
\end{tabular}

(1) Deputies and Senators (2) Top Public Officials (3) Business Leaders (4) Labour Union Leaders. 
Third comes poverty. Added together, health and education, poverty, and income distribution totalled 38.5 per cent of the responses.

Next, we asked what should be the major national goals for the near future. As indicated in Table 3, once again improving education comes high, actually now by far the most popular answer among the elites. To eradicate poverty and reduce inequality came third in the preferences, preceded by 'to reduce the size of government'. Here it is interesting to observe significant variations among elite sectors. This was not the case though when inquired about priorities for the future. Education was significantly more popular among top public officials and business leaders than among politicians and union leaders. The second aggregated preference, to reduce the size of the state, galvanizes business views, but it is also popular among politicians, while not very popular among top public officials, and even less so in the union circles. This should not surprise us, as top public officials are the state actors, while union leaders are intrinsically connected to the state machine as heirs of the country's long established corporatist tradition. Somewhat surprising is the observation in Table 3 that more recent issues in the public agenda, such as market integration with Brazil's neighbouring countries (Mercosur) and environmental protection, do not strike elite members from any of the four sectors as relevant national objectives.

Table 3: Major national goals in the near future (\%)

\begin{tabular}{lccccc}
\hline \multicolumn{1}{c}{ Goal } & $\begin{array}{c}\text { Total } \\
\text { sample }\end{array}$ & $(1)$ & $(2)$ & $(3)$ & $(4)$ \\
\hline Increase educational levels & 23.0 & 14.8 & 24.7 & 29.8 & 18.5 \\
Reduce size of the State & 18.2 & 22.2 & 13.5 & 33.0 & 3.7 \\
Reduce poverty and inequality & 17.6 & 25.9 & 19.1 & 9.6 & 19.8 \\
$\begin{array}{l}\text { Increase popular participation in political } \\
\text { decisions }\end{array}$ & 16.4 & 5.6 & 14.6 & 5.3 & 38.3 \\
$\begin{array}{l}\text { Preserve the democratic regime } \\
\text { Guarantee economic growth }\end{array}$ & 11.3 & 20.4 & 7.9 & 8.5 & 12.3 \\
Integrate the economy into international & 9.7 & 7.3 & 14.6 & 10.6 & 4.9 \\
market & 2.2 & 1.9 & 2.2 & 3.2 & 1.2 \\
Keep order & 0.9 & 1.9 & 2.2 & --- & --- \\
$\begin{array}{l}\text { Further integrate the country into } \\
\text { mercosur }\end{array}$ & 0.3 & --- & 1.1 & --- & --- \\
Protect the environment & 0.3 & --- & --- & --- & 1.2 \\
Total & 99.9 & 100.0 & 99.9 & 100.0 & 99.9 \\
& $(\mathrm{n}=318)$ & $(\mathrm{n}=54)$ & $(\mathrm{n}=89)$ & $(\mathrm{n}=94)$ & $(\mathrm{n}=81)$ \\
\hline
\end{tabular}

(1) Deputies and Senators (2) Top Public Officials (3) Business Leaders (4) Labour Union Leaders.

When asked to choose among various initiatives to reduce poverty, the preferred alternative seems to contradict the usual assumption that elites are against land redistribution. Thus, as shown in Table 4, agrarian reform - deemed to be favoured just by the extreme left - is the most attractive option for all but the business sector. The motivation behind such preference only became clear to me in the next stage of the research, when interviewers gave open answers to semi-structured questions, as I will 
comment in the next section. Except for union leaders, the second most chosen alternative was to increase the efficiency of public administration, particularly popular among businesses leaders and politicians. Consistent with their structural position, business leaders are the only ones to reveal high preference for population control and state deregulation. But none of the four sectors show significant preference for more bold initiatives to reduce poverty and inequality. The percentage of individual elite members who favour more progressive taxation, expanded social expenditures, profit sharing for workers, and wealth taxation is low among the four groups, even though the variations among them seem to reflect their functional position.

Table 4: Priority initiatives for reducing inequality (\%)

\begin{tabular}{lccccc}
\hline \multicolumn{1}{c}{ Initiative } & $\begin{array}{c}\text { Total } \\
\text { sample }\end{array}$ & $(1)$ & $(2)$ & $(3)$ & $(4)$ \\
\hline Promote agrarian reform & 31.1 & 35.3 & 32.6 & 6.8 & 53.8 \\
$\begin{array}{l}\text { Increase the efficiency of } \\
\text { public social services }\end{array}$ & 16.4 & 21.6 & 17.4 & 21.6 & 6.3 \\
$\begin{array}{l}\text { Control population growth } \\
\text { Deregulate the economy }\end{array}$ & 13.4 & 7.8 & 14.0 & 26.1 & 2.5 \\
$\begin{array}{l}\text { Increase progressiveness of } \\
\text { income tax }\end{array}$ & 10.2 & 5.9 & 4.7 & 26.1 & 1.3 \\
$\begin{array}{l}\text { Increase social expenditures } \\
\text { Implement profit-sharing }\end{array}$ & 8.5 & 11.8 & 12.8 & 9.1 & 5.0 \\
schemes for labour & 8.2 & 9.8 & 10.5 & 5.7 & 8.8 \\
Tax wealth & 2.6 & 5.9 & 5.8 & 3.4 & 17.5 \\
Total & 99.9 & 100.1 & 100.1 & 99.9 & 100.2 \\
& $(\mathrm{n}=305)$ & $(\mathrm{n}=51)$ & $(\mathrm{n}=86)$ & $(\mathrm{n}=88)$ & $(\mathrm{n}=80)$ \\
\hline
\end{tabular}

(1) Deputies and Senators (2) Top Public Officials (3) Business Leaders (4) Labour Union Leaders.

The survey also sought to investigate what the elites deemed desirable and/or viable to enforce in order to reduce poverty and inequality. Do they believe it is possible to do something to ameliorate the fate of the poor? And would they support the adoption of such measures? The answers to such questions are shown in Table 5.

Looking at Table 5, we observe that from a purely normative perspective (first and second columns) 60 per cent or more of the elites affirm that every social policy but the last is desirable. Moreover, the proportion of those who classify the policies in question as both desirable and viable is always quite high, implying that the elites must have some dose of confidence in the potential of these social policies. Why then do social policies fail to meet their objectives? Table 6 summarizes the answers obtained for this open-ended question.

When asked why social policies have not been able to reduce poverty and inequality, the large majority blames public authorities for bad planning and execution, as illustrated in Table 6. Somewhat surprisingly, the second most chosen alternative, lack of political will and/or low commitment, is popular even among political leaders whom one would expect to be the most likely to mobilize political will. Next in the general preference comes personal use of resources or egoism, but, this time, the ones who 
confer more importance to this motive are business and union leaders. Also worth noting is the fact that non-voluntary factors, like structural economic problems and 'resource scarcity', are not perceived by many as reasons for social policy failure.

Table 5: Viability and desirability of particular social policies (\%)

\begin{tabular}{lccccc}
\hline Policy & V/D & D/N & V/N & N/N & Total \\
\hline Free and universal basic education & 85.5 & 11.0 & 3.2 & 0.3 & 100.0 \\
Popular housing programmes & 80.3 & 13.3 & 3.2 & 3.2 & 100.0 \\
Free universal access to health services & 56.9 & 36.7 & 3.2 & 3.2 & 100.0 \\
Early retirement* & 52.6 & 15.9 & 11.4 & 20.1 & 100.0 \\
Unemployment insurance & 48.5 & 39.2 & 6.5 & 5.8 & 100.0 \\
Food distribution programmes & 35.6 & 24.8 & 21.8 & 17.8 & 100.0 \\
$\begin{array}{l}\text { Free university education } \\
\text { Minimum income for everyone above }\end{array}$ & 35.1 & 37.4 & 8.5 & 19.0 & 100.0 \\
$\begin{array}{l}\text { age 25 } \\
\text { Old-age pension regardless of previous }\end{array}$ & 27.8 & 39.2 & 26.1 & 30.4 & 100.0 \\
contribution & 9.4 & 24.7 & 3.9 & 62.0 & 100.0 \\
\hline
\end{tabular}

V/D: viable and desirable; $\mathrm{V} / \mathrm{N}$ : viable but not desirable

$\mathrm{D} / \mathrm{N}$ : desirable but not viable; N/N: neither desirable nor viable

* Refers only to early retirement under federal laws that permit women and men to retire after 30 and 35 years of service, respectively, regardless of age.

In short, a large majority of elites points to either mismanagement or attitudinal aspects rather than to objective structural constraints as major explanations for the failure of social policies. The idea that bad planning and/or policy mismanagement are ranked first among the reasons for failure is somehow intriguing, particularly among the bureaucratic elite in charge of planning and enforcement. The same is true of the second most-cited answer, lack of political will, which not only union leaders but also politicians and top bureaucrats named as among the most important factors behind policy failure.

At first glance, the data presented here may suggest a rather contradictory picture: the elites seemingly feel that social issues are of great relevance, indeed deeming them to be among the most important obstacles to democracy in addition to constituting a key national problem in and of themselves. Moreover, as Table 5 shows, several policies aimed at fighting poverty and providing some form of social protection are classified as both desirable and viable. Yet, at the same time, a large proportion of the elite claims that social policies fail due to a lack of political will, opportunistic misuse of social programmes, and a lack of social conscience.

I suggest, however, that no contradiction exists. It is to be expected that, from the perspective of the strategic elites, the roles played by will, decision-making, and policy management will be deemed paramount. Going even further, I suggest that the very predominance of a concern over 'voluntaristic' versus 'structural' factors as exhibited by the elites attests to their recognition of the extreme concentration of social, economic, and political resources in Brazil. In other words, conscious of the gravity of poverty problems, and also of the acute social inequalities prevailing in the country, elite members are also deeply aware of their monopoly privileges. 
Table 6: Why social policies do not meet their objectives

\begin{tabular}{|c|c|c|c|c|c|}
\hline Reason & $\begin{array}{l}\text { Total } \\
\text { sample }\end{array}$ & 1 & 2 & 3 & 4 \\
\hline Bad planning/execution & 29.3 & 34.6 & 33.7 & 33.7 & 16.0 \\
\hline Lack of political will/low priority & 18.8 & 19.2 & 19.1 & 14.1 & 23.5 \\
\hline $\begin{array}{l}\text { Political and/or personal use } \\
\text { of these policies }\end{array}$ & 12.7 & 7.7 & 4.5 & 15.2 & 22.2 \\
\hline Corruption & 8.6 & 9.6 & 10.1 & 6.5 & 8.6 \\
\hline Characteristics of the elite* & 5.4 & 5.8 & 5.6 & 2.2 & 8.6 \\
\hline $\begin{array}{l}\text { Paternalistic and/or palliative } \\
\text { nature }\end{array}$ & 5.7 & 7.7 & 5.6 & 6.5 & 3.7 \\
\hline $\begin{array}{l}\text { State concentrates on other } \\
\text { areas }^{\star \star}\end{array}$ & 5.4 & 3.8 & 4.5 & 7.6 & 4.9 \\
\hline Lack of resources ${ }^{\star \star *}$ & 4.5 & 3.8 & 6.7 & 4.3 & 2.5 \\
\hline $\begin{array}{l}\text { Lack of participation by civil } \\
\text { society }\end{array}$ & 3.8 & --- & 5.6 & 4.3 & 3.7 \\
\hline Economic structural problems & 2.2 & 5.8 & 1.1 & 1.1 & 2.5 \\
\hline $\begin{array}{l}\text { Greater private sector } \\
\text { Participation in execution }\end{array}$ & 1.3 & 1.9 & --- & 3.3 & --- \\
\hline Others & 2.2 & --- & 3.4 & 1.1 & 3.7 \\
\hline Total & $\begin{array}{c}99.9 \\
(n=314)\end{array}$ & $\begin{array}{c}99.9 \\
(n=52)\end{array}$ & $\begin{array}{c}99.9 \\
(n=89)\end{array}$ & $\begin{array}{c}99.9 \\
(n=92)\end{array}$ & $\begin{array}{c}99.9 \\
(n=81)\end{array}$ \\
\hline
\end{tabular}

(1) Deputies and Senators (2) Top Public Officials (3) Business Leaders (4) Labour Union Leaders.

* Selfishness, short-sightedness, authoritarianism, etc.

** i.e., the state is too big and also too involved in direct economic activity, thereby diverting human and capital resources from social areas.

*** This item implied no critique of the activities of the State as such, but, rather, pointed to a scarcity of funds for enforcement of social policy.

What the data does seem to suggest is that elite members are aware of their privileged position if they wish to alter the status quo. But a separate question remains: what incentives would the elites have for introducing changes? They are most certainly aware of the risks posed by excessive poverty and inequality. Thus, for example, when asked to name the worst consequence of poverty in large cities, a significant majority mentioned violence, crime, and insecurity, as indicated in Table 7.

The data suggest that Brazil's strategic elites see the urban poor as a 'dangerous class'. However, there is nothing to indicate what factors might explain their concomitant lack of collective willingness to attack social problems. Based on this survey, we can only speculate as to what might make the elites sensitive to the acute social problems Brazil faces, while remaining unable/unwilling to promote a concerted effort to change the situation. 
Table 7: Worst consequences of poverty in large cities

\begin{tabular}{lccccc}
\hline Consequence & $\begin{array}{c}\text { Total } \\
\text { sample }\end{array}$ & 1 & 2 & 3 & 4 \\
\hline Violence/crime/insecurity & 51.6 & 64.1 & 49.4 & 44.8 & 55.9 \\
Dehumanization/social apartheid & 10.2 & 7.7 & 6.2 & 13.8 & 11.8 \\
Social conflict/social chaos risk & 8.4 & 7.7 & 9.9 & 11.5 & 2.9 \\
Declining quality of life & 5.5 & 2.6 & 8.6 & 6.9 & 1.5 \\
Social misery & 5.1 & 5.1 & 3.7 & 2.3 & 10.3 \\
Unemployment & 4.4 & 5.1 & 1.2 & 4.6 & 7.4 \\
Vicious circle of poverty & 4.0 & 2.6 & 6.2 & 5.7 & --- \\
Hindrances to development & 2.9 & --- & 3.7 & 3.4 & 2.9 \\
Housing problem (Shantytowns) & 2.2 & --- & 3.7 & --- & 4.4 \\
Threat to democratic stability & 1.5 & 2.6 & 2.5 & 1.1 & --- \\
Encourages political opportunism & 1.1 & --- & 1.2 & 1.1 & 1.5 \\
Others & 3.3 & 2.6 & 3.7 & 4.6 & 1.5 \\
& & & & & \\
Total & 100.2 & 100.1 & 100.0 & 99.8 & 100.1 \\
& $(\mathrm{n}=275)$ & $(\mathrm{n}=39)$ & $(\mathrm{n}=81)$ & $(\mathrm{n}=87)$ & $(\mathrm{n}=68)$ \\
\hline
\end{tabular}

(1) Deputies and Senators (2) Top Public Officials (3) Business Leaders (4) Labour Union Leaders.

Based on a pattern that emerged in Table 7, we might suggest that often it may be hard to move from the individual to the collective level. This is to say, many elite members placed emphasis on the individual negative consequences of poverty, such as crime and lack of security, whereas a much smaller proportion of the elites pointed to its collective negative consequences (social conflicts/social chaos), and this may reflect the individualized/fragmented social identity of both elites and masses. In any case, the observations gathered through survey analysis prompted me to search for further information about the view of the elites. Further inquiry might contribute towards clarifying this apparent dissociation between social awareness and social responsibility that elites display.

\section{In-depth study: elites' repertoires to evaluate poverty and inequality}

As already mentioned, the second stage of the project made use of different tools. Finding it difficult to answer the stated research questions just with survey data, surveys were combined with qualitative data gathered through in-depth interviews with 80 elite members based in four regional states, two in the more prosperous Center-South (Sao Paulo and Rio de Janeiro), and two in the impoverished Northeast (Ceará and Bahia). The selection was primarily based upon institutional positions, but with a deliberate attempt to introduce sector diversification. In addition to the four categories used in the survey (politicians, top public officials, business leaders and union leaders), interviews also included opinion makers, intellectuals, religious leaders, and high-ranking members of the military. There was also a deliberate inclusion of elite women, while in the random sample no woman was selected. Moreover, the formation of a research team to replicate the study in four other countries with acute problems of poverty and inequality 
made it possible to use the discourses of different national elites as comparative instruments (Reis and Moore 2005).

The interview guide replicated to some extent the survey questionnaire, but naturally there was no forced sequence, and no open-ended responses were demanded. The idea was precisely to let the informants freely voice their general views, their value preferences, social cognitions, and normative prescriptions. I conducted all the interviews, but most of the time shared the experience with a colleague who helped to ensure that all topics were covered, while, at the same time, the interviewee was free to develop the questions and to connect ideas as they saw fit.

As in many such studies, apart from the content of their discourses, the script that the respondents used to express their views, the concepts and images they took for granted, and their recurring images was also of interest. Though the interview sample was not random, the idea was to look at the information, seeking to map out the recurring observations, standard responses, significant variations, in short, to obtain an impressionistic map of the views of people in top institutional positions about poverty and inequality. In fact, after a series of long open discourses about the same topics, it was as if the interviewer had reached a saturation point in the information (Lamont 2000; Swidler 1986). In this effort to map out general outlooks, the comparison with elites elsewhere was of paramount importance. Much of what is stated here about the views of Brazilian elites was made clear by looking at the discourses of the other national elites. Looking at converging and diverging images here and there, it was possible to get sort of mirror images for national elites.

Going through the discourse of Brazilian elites, the salience of education for improving the conditions of the poor is the most obvious observation. The preference for schooling as the best strategy to overcome poverty, which we observed while analyzing the survey data, now seems even stronger. Even sectors that indicated other initiatives as priorities, in the open responses, they ended up indicating that educational policies are the condition sine qua non for other initiatives to become viable and efficient. Further inquiring into the reasons for such preference, one realizes that, underneath it, there is a strong preference for equality of opportunity vis-à-vis equality of conditions, not to mention equality of results. This is also confirmed in the elites' lack of sympathy for affirmative action initiatives. Particularly when asked about the recent adoption of quotas for students from discriminated groups by some public universities, the elites unanimously expressed their disapproval, and voiced their belief in the moral superiority of universal policies. They are convinced that educational policies constitute instruments that can assure generalized upward mobility without implying losses for other social groups.

This idea that an educated poor will then acquire the major instrument to move up in the social ladder seems never confronted with the actual demand for labour. Whenever asked who would grant jobs to the educated poor, elite members mentioned the low quality of the labour force as the major explanation for widespread, disguised or open unemployment. In fact, this biased view towards labour supply seems to be widely shared by the international policy community. As Amsden (2010) convincingly argues, in most of the less developed world little or no emphasis has been placed on expanding labour demand as an instrument to reduce poverty. In her view, this myopic view seriously compromises the success of anti-poverty initiatives. 
But, by comparing across countries, it is possible to tell more about the preference for investments in education. Thus, the responses for Brazil made it very clear that education is chosen mainly for its instrumental value: you acquire it to use in the labour market, to improve your professional profile so as to earn a better income. It is essentially a direct investment in upward mobility. This perception contrasts sharply with the recurring view among Bangladeshi elites, who see education primarily as an empowerment mechanism. For them, access to education enables the poor to develop awareness of their social condition, to get organized to demand their citizenship rights, to become autonomous subjects (Hossain and Moore 2000).

When asked who should provide the resources to expand educational opportunities, the answer is invariably 'the government'. Would they agree to pay more taxes to make government tasks possible? 'Of course not, we already pay too many taxes'. The various discourses repeat again and again, in different ways, the same message that one of them summarizes in a few words:

Even a very poor child, if she gets a good education and works hard, she will certainly improve her living conditions and will have the chance to overcome poverty. If education is provided, inequality will gradually be reduced because everybody will have better wages, better job positions. ... No, there is no need to increase taxation. If the government is really committed, it is possible to provide better education. It is a question of political will.

The issue, 'political will', already explored in the survey, is repeated here as well. But now it is possible to ask who precisely is the actor that should exert political will, but fails to do so. The answers come quickly and they are converging: the major fault for lack of will is attributed to the state or to the government that are used as synonyms by most respondents. Even when the elite members are part of the government, like the top bureaucrats in the sample, or members of the political elite, they do not perceive themselves as part of the establishment. The vision of the state as 'up there' is recurrent, suggesting that no feeling of public responsibility exists.

It is interesting to compare the lack of public responsibility just commented with some sort of personalized social responsibility that is widely generalized among the elites. Just a small minority of the interviewees did not report experiences of helping the poor. But, it is consistently some individual or family that the elite member has personal contacts with, as if social responsibility did not extend beyond the limits of face-to-face contact. As we also observed in the Philippines, Brazilian elites seem to feel responsible for personal acquaintances, not for fellow citizens (Clarke and Marites 2000). However, there are also differences in the way elites in the two countries perceive the poor. For elites in the Philippines, helping the poor seems to be part of a patronage tradition that is strongly institutionalized and is accepted as part of one's social and political obligation, and it is rewarded with social prestige.

Among the Brazilian elites, personal patronage is less visible and less attached to prestige for the patron. Moreover, elites in the Philippines tend to report their private dispensation of favours as an internalized social obligation, something they have to do because they are better-off. In turn, in the discourse of the Brazilian elites, the description of similar initiatives always emphasizes that they help those who show the desire to strive for a better life, those who know how to take advantage of opportunities 
offered to them. While the issue about deserving and non-deserving poor is not visible in the public sphere, it is recurrent in the elites' elaborations about their private world.

In short, Philippine elites openly refer to their dependents, while the Brazilians seldom use the word dependency, stressing instead that they help those who seem to be able to become independent, provided that some stimulus is granted. If, in both cases, elites feel responsible for personal acquaintances, can we label them both paternalistic? Maybe, but this is not what should concern us here. The important issue is to explore how this personalized commitment could be generalized so as to be converted into a civic notion of responsibility.

Cross-national comparison allows us to observe that Brazilian elites are much more likely to pass responsibility onto the state than elites in Bangladesh. The latter usually considers civil society organizations as the key actors to implement anti-poverty measures (Hossain and Moore 2000). In particular, they show strong preference for NGOs that they perceive more apt and more suitable to undertake social functions. Brazilian elites, in turn, are convinced that it is the state's moral responsibility to provide for the poor. And even if they evaluate the state's performance as faulty, they also see it, in principle, as the most adequate locus to enforce measures to reduce poverty. Even those who defend civil society partnership in this task make it clear though that the leadership belongs to the state. The large majority reveal, implicitly or explicitly, some suspicion about NGOs. While in Bangladesh such organizations are perceived as virtuous and efficient, here they are often portrayed as opportunistic, and for some even corrupt.

Two possible explanations surface when confronting these differences between the views from the top of the social hierarchy in Brazil and Bangladesh. On the one hand, one could expect that the broader cultural differences between the two countries create room for such disparate views. One could argue, for example, that the core values of predominant religions in the two countries would be translated into different dispositions for viewing social policy. The centrality of charity in Islam would find in voluntary associations the natural channel of action. In turn, the Iberian-Catholic ethos in the Brazilian context would be conducive to a paternalistic outlook that finds easy elective affinities with the idea of a centralized authority responsible for taking care of the poor.

While plausible, the cultural explanation mentioned above does not answer why such values and perceptions about the role of state and civil society remain unchanged. As in most cultural explanations, this one also needs to be explained. Perhaps equally important to explain the different views we find in Brazil and in Bangladesh is the degree of institutionalization of the state. That in Bangladesh the NGOs sector employs more people than the public sector is a strong indication that elite preference for societal organizations might derive from a realistic assessment of the available institutional resources (Reis and Moore 2005). In the Brazilian case, the long tradition of a centralized state, the historical role of the state in the economy, are not only cultural traditions, but also real institutional legacies, so much so that NGOs themselves are often co-opted by the state (Reis 2009).

Land reform, another alternative anti-poverty policy that is salient in the survey, is widely mentioned by Brazilian elites as a desirable strategy to fight poverty. This seems 
a major change if one recalls that the fear elites and upper classes displayed of popular demands for agrarian reform in the 1960s was a crucial factor in justifying the military coup that brought the army into power for over 20 years. If, as observed in the survey, this policy preference is not high among business leaders, even among them there are supporters of land redistribution.

Further inquiring into this preference, a simple answer emerges: land reform is perceived as a way 'to send the poor' back to the countryside. This is compatible with their argument regarding declining living conditions in large urban centers in general. In particular, the idea that violence and criminality are the worst consequences of poverty goes hand and hand with the conclusion that the poor should have remained in the countryside. Even if concretely large contingents of poor urbanites have never lived in rural areas, in the imaginary of the elites, the overload of demands the poor pose for services and welfare provisions are major determinants of urban problems. In turn, in the countryside the destitute could cultivate their own plots and live better. Although empirical evidence shows that poverty is even more severe in rural areas, the image of a self-supporting poor, secluded in their own world is a widespread ideal image for elite members. As in the case of education, here too the state is perceived as the actor that can do and must pay for the solution.

We found similar images in the case of contemporary South African elites who would also prefer removing the poor from their surroundings (Kalati and Manor 2000). In fact, the similarities in the views of the elites in Brazil and South Africa are not restricted to the idealization of living conditions for the poor in rural areas. They share a liberal view expressed mainly in the preference for education as the most desirable and adequate way to address poverty issues. Both national elites see the state as the legitimate actor to conduct anti-poverty measures, and both somehow mistrust the protagonism of NGOs. But, there are also noticeable differences among them. Thus, while Brazilian elites reveal an accurate cognition of the magnitude of inequality in their context, South African ones tend to deny that they have a very unequal stratification structure. In the Brazilian study, nearly every single respondent spontaneously referred to the fact that the country is among the most unequal in the world. In contrast, many of the informants in the South African case tend to state that they were not like Brazil or India, the two countries they considered really unequal. While they were correct about the inequality rank in the case of Brazil, the same was not true of India, which presents inequality levels lower than those in South Africa.

Another close similarity between Brazil and South Africa refers to the identification of poverty externalities. Here and there, they affirm without hesitation that there are clear negative consequences of poverty for the non-poor. In both contexts, the poor are perceived as constituting a 'dangerous class'. However, different from the outlook of European elites during the modernization process, what is feared is private, not collective, violence. Fear of riots, revolts and revolution does not exist in the mental horizon of both national elites. They fear threats to personal security and to private property. Once again, the contrast provided by the Bangladeshi case is noticeable. The elites there tend to see violence and criminality as caused not by the poor, but rather by the greedy middle classes. In their perception, poor people are the repository of the country's original virtues, the purest and most honest sector of the population. The elites contrast the simple values and motivations of the poor against the consumerism of the middle class that want to imitate Western patterns of consumption. 


\section{Prospects for expanding the elites' social responsibility?}

In the previous pages, de Swaan's framework of analysis, has led us to argue that, moved by fear of individual or collective violence, by profit considerations that demand better workers and more consumers, or by any other reasons for acting, elites may look at poverty and even inequality as problematic, and feel inclined to support anti-poverty initiatives. Whether measures will be taken to ameliorate the lot of the poor depends upon the willingness of those who control symbolic and material resources. Following de Swaan (1988), the data maintains that social policies depend upon the formation of a 'social consciousness', which can be defined as a set of perceptions conducive to the adoption of measures to reduce poverty. Social consciousness is not synonymous to good will, philanthropy, charity, or similar notions. It does imply that the problem of poverty is perceived as one that creates negative externalities, it is the elites' business, and can realistically be tackled. In other words, it entails (a) a belief in social interdependence, (b) a sense of responsibility, and (c) an assessment that it is possible to change the status quo and it is worth acting accordingly (de Swaan et al. 2000).

It is also important to bear in mind that to say that elites affect policy decisions is not to say that every elite member is a decision-maker. Some do indeed act in that capacity, but others are relevant because they influence decision-makers, form public opinion, have the means to act in order to make policies effective, etc. Moreover, the various sectors of the elite may have different perceptions of poverty and inequality issues, and the very margin of non-consensual views could play a role in shaping distribution patterns. This suggests that research efforts to compare the views of different elite sectors may contribute to our knowledge of how to devise more effective policies.

Evidence from Brazilian elites suggest that the poverty issue is highly salient in their perceptions. In different contexts, while asked to identify the country's major problems, they mention poverty-related issues among the most relevant. We observed that, essentially, they fear threats to private property and personal security. No mention is made of the risk of contagious diseases, something that should not surprise us given the medical progress the world has experienced. Nor are we surprised to find out they do not fear popular revolt, which has become, for the time being at least, an unlikely answer to destitution. Elites show little concern too about shortages of qualified labour or about a less dynamic consumer market, aspects that are often mentioned by specialists as real limitations to the country's growth.

Possible explanations here are the combined effects of abundant low skilled labour, plus the long experience of state protection that suppressed the need for competitiveness. Be that as it may, even if the threats they identify are not similar to the ones that seemed originally to have moved elites in developed countries to adopt anti-poverty measures, there is strong awareness among them of the negative externalities of poverty. So the first of the conditions prompting elites to act, the development of a sense of social interdependence, does exist.

Next, we observe that elites also believe that anti-poverty measures are viable. They list investments in education, health, land distribution, and other initiatives as feasible ways to improve the lot of the poor. Therefore, also the second condition, to engage in action, provides viable solutions, is present in the elites' assessment. But it is the third condition of de Swaan's model, the sense of social responsibility that seems to be the 
fragile element in engaging elites in social policy. As we observed, civic commitment is low among elite members who pass the responsibility onto a state they portray as a distant and abstract entity when dealing with poverty is at stake. Even those who are part of the state apparatus, or are active in government, deny being part of the super entity that, in their view, should look after the poor.

Frustrating as the above observation may be for those who seek to mobilize social support, the varying historical conditions of the state-building process may perhaps be part of the explanation for the observed differences. The elites who acted to lay the grounds for welfare initiatives were active in the constitution of their nation-states (Moore 1966; Bendix 1977). Current Brazilian elites cannot be said to play similar roles, nor did their historical antecessors. The historical process of nation and state building in Brazil shows a very different pattern from the Western European one: while the state was instituted by former colonial authorities, the nation-building process lagged much behind, and is actually still under completion (Reis 1998; Schwartzman 1982). But if the historical origins of the nation-state play an explanatory role, there is no reason to assume that it explains it all, nor that a sense of social responsibility is forever prevented among elites. There are already signs that things are changing, albeit small ones. Thus, the slow spread of corporate social responsibility as a business ideology suggests that elites are reacting in new ways to social demands. Again, it does not matter if the changed attitudes reflect pure interest motivation, as social activists claim. To the extent that they start to feel committed, we may conclude that a sense of social responsibility is emerging.

To conclude with, both the survey data and the in-depth interviews suggest that the views of the elites we investigated in Brazil display perceptions about poverty that do not exactly repeat what de Swaan (1988) describes for Western European and American Elites in his historical analysis. That is to say, Brazilian elites seem to have developed an incomplete social consciousness in de Swaan's terminology, insofar as they acknowledge that poverty has negative externalities, believe it is feasible to counteract them, but do not feel personally committed to generalized action. While the tentative explanation suggested here is grounded in the historical roots of the nation-states, this is certainly not the whole story. The conditions that have prevented the completion of a social consciousness have to be searched for in historical processes. The differences identified need to be further explored if we want to get more insights into elite views. Moreover, systematic comparison in time and space may also help us formulate hypotheses about the prospects for anti-poverty schemes as the social fabric faces old and new pressures. Could we expect elites to assume social responsibility when they themselves are hard hit by market downturns? Or could we expect that the generalized fragility across the social spectrum may make the elites more aware of social interdependence? Awareness of interdependence itself may be conducive to stronger feelings of social responsibility.

Last but not least, the reasoning used here to discuss a particular national elite can certainly be used to speculate if elites worldwide are developing a sense of responsibility vis-à-vis global problems. To the extent that global processes significantly increase societal interdependence, we ought to observe if elites are increasing their awareness of such an effect, and if they are moving to seek collective feasible mechanisms. Naïve as such a statement is, it is not different from the general values that lay behind social sciences. We look at the historical process and inquire into 
the conditions for change because we believe it is possible to sustain hope for a better world.

\section{References}

Amsden, A. H. (2010). 'Say's Law, Poverty Persistence, and Employment Neglect'. Journal of Human Development and Capabilities, 11 (1): 57-66.

Barros, R. P., R. Henriques, and R. Mendonça (2000). 'The Unacceptable Stability: Inequality and Poverty in Brazil'. In R. Henriques (ed.) Desigualdade e Pobreza no Brasil. Rio de Janeiro: IPEA, pp. 21-47.

Bendix, R. (1977). Nation-Building and Citizenship. Berkeley: University of California Press, 2nd edn.

Clarke, G., and S. Marites (2000). 'Voices from the Top of the Pile: Elite Perceptions of Poverty and the Poor in the Philippines'. In E. P. Reis and M. Moore (eds) (2005). Elite Perceptions of Poverty and Inequality. London: Zed Books.

De Swaan, A. (1988). In Care of the State: Health Care, Education and Welfare in Europe and the USA in Modern Era. London: Polity Press.

De Swaan, J. Manor, E. Oyen, and E. Reis (2000). 'Elite Perceptions of the Poor: Reflections on a Comparative Research Project'. Current Sociology, 48 (1): 43-56.

Ellwood, D. (1988). Poor Support: Poverty in the American Family. New York: Basic Books.

Hossain, N., and M. Moore (2000). 'So Near and Yet So Far: Elites and Imagined Poverty in Bangladesh. In E. P. Reis and M. Moore (eds) (2005). Elite Perceptions of Poverty and Inequality. London: Zed Books.

Kalati, N., and J. Manor (2000). 'Elite Perceptions of Poverty and Poor People in South Africa'. In E. P. Reis and M. Moore (eds) (2005). Elite Perceptions of Poverty and Inequality. London: Zed Books.

Lamont, M. (2000). The Dignity of Working Men: Morality and the Boundaries of Race, Class, and Immigration. Cambridge, MA: Harvard University Press.

Lewis, O. (1959). Five families; Case Studies in the Culture of Poverty. New York: Basic Books.

Lewis, O. (1966). La Vida: A Puerto Rican Family in the Culture of Poverty. New York: Random House.

Lima, M. R., and Z. B. Cheibub (1994). 'Elites Estrategicas e Dilemas do Desenvolvimento’. Rio de Janeiro: IUPERJ.

Moore Jr., B. (1966). Social Origins of Dictatorship and Democracy: Lords and Peasants in the Making of the Modern World. Boston: Beacon Press.

Munch, R. (1992). 'The Production and Reproduction of Inequality: A Theoretical Cultural Analysis'. In R. Munch and N. J. Smelser (eds), Theory of Culture. Berkeley: University of California Press. 
Reis, E. P., and Z. B. Cheibub (1995). 'Elites, Cultura Política e Consolidação Democrática’. DADOS, Revista de Ciências Sociais, 38 (1): 31-56.

Reis, E. P., and Z. B. Cheibub (1996). 'Bureaucratic Elite, Political Culture, and Democratization in Brazil’. Nova Economia, 6 (1): 143-62.

Reis, E. P. (1998). 'Elites Agrárias, State-Building e Autoritarismo’. In E. P. Reis (ed.), Processos e Escolhas, Ensaios de Sociologia Politica. Rio de Janeiro: ContraCapa.

Reis, E. P. (2000). 'Percepções da Elite sobre Pobreza e Desigualdade'. In R. Henriques (ed.), Desigualdade e Pobreza no Brasil. Rio de Janeiro: IPEA, pp. 487-500.

Reis, E. P., and M. Moore (eds) (2005). Elite Perceptions of Poverty and Inequality. London: Zed Books.

Reis, E. P. (2009). 'New Ways of Relating Authority and Solidarity: Theoretical and Empirical Explorations'. In A. Denis and D. Kalekin-Fishman (eds), The ISA Handbook in Contemporary Sociology. London: Sage.

Schwartzman, S. (1982). Bases do Autoritarismo Brasileiro. Rio de Janeiro: Editora Campus.

Small, M., and K. Newman (2001). 'Urban Poverty After The Truly Disadvantaged: The Rediscovery of the Family, The Neighborhood, and Culture'. Annual Review of Sociology, 27, 23-45.

Swidler, A. (1986). 'Culture in Action: Symbols and Strategies'. American Sociological Review, 51: 273-86.

Verba, S., and G. Orren (1985). Equality in America: The View from the Top. Cambridge, MA: Harvard University Press.

Verba, S., with S. Kelma, G. R. Orren, I. Miyake, J. Matakuki, I. Kabashima, and D. G. Ferree Jr. (1987). Elites and the Idea of Inequality: A Comparison of Japan, Sweden and the United States. Cambridge, MA: Harvard University Press.

Wilson, R. (1992). Compliance Ideologies, Rethinking Political Culture. New York: Cambridge University Press. 